\title{
Ohmic heating of strawberry products: electrical conductivity measurements and ascorbic acid degradation kinetics
}

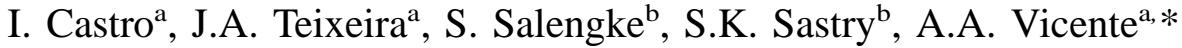 \\ ${ }^{\mathrm{a}}$ Centro de Engenharia Biológica, Universidade do Minho, Campus de Gualtar, 4710-057 Braga, Portugal \\ ${ }^{\mathrm{b}}$ The Ohio State University, Department of Food, Agricultural and Biological Engineering, 590 Woody Hayes Drive, Columbus,
} OH 43210-1057, USA

Received 31 May 2003; accepted 6 November 2003

\begin{abstract}
The effects of field strength and multiple thermal treatments on electrical conductivity of strawberry products were investigated. Electrical conductivity increased with temperature for all the products and conditions tested following linear relations. Electrical conductivity was found to depend on the strawberry-based product. An increase of electrical conductivity with field strength was obvious for two strawberry pulps and strawberry filling but not for strawberry topping or strawberry-apple sauce. Thermal treatments caused visible changes (a decrease) in electrical conductivity values of both strawberry pulps tested, but the use of a conventional or ohmic pre-treatment induces a different behavior of the pulps' conductivity values. Ascorbic acid degradation followed first order kinetics for both conventional and ohmic heating treatments and the kinetic constants obtained were in the range of the values reported in the literature for other food systems. The presence of an electric field does not affect ascorbic acid degradation.
\end{abstract}

(c) 2003 Elsevier Ltd. All rights reserved.

Keywords: Strawberry products; Electrical conductivity; Field strength; Ascorbic acid; Kinetics

Industrial relevance: Due to the ability of the ohmic heating technologies to achieve rapid and reasonably uniform heating of electrically conductive materials its impact on food quality is of interest. This study shows interesting relationships between heat treatment and electrical conductivity of strawberry pulps and also suggested the product dependency for optimum ohmic heating applications.

\section{Introduction}

The ohmic heating concept is not new and was widely used in the XIX century to pasteurize milk. Apparently due to the lack of inert materials for the electrodes this technology was abandoned (exception made for electroconductive thawing, Mizrahi, Kopelman \& Perlaman, 1975). Ohmic heating technology has recently gained new interest because the products obtained are of clearly superior quality than those processed by conventional technologies. This is mainly due to its ability to heat materials rapidly and uniformly leading to a less aggressive thermal treatment (which, otherwise, often leads to over processed volumes). Ohmic heating can be consid-

\footnotetext{
*Corresponding author: Tel.: +351-253-604-419; fax: + 351-253678-986.

E-mail address: avicente@deb.uminho.pt (A.A. Vicente).
}

ered a high temperature short time (HTST) aseptic process. The potential applications of this technique in food industry are very wide and include, e.g. blanching, evaporation, dehydration, fermentation (Sastry et al., 2001) and pasteurisation.

Ascorbic acid (vitamin C) is a very important nutrient, being essential, e.g. for the synthesis of collagen. The lack of this vitamin leads to scurvy (Gregory, 1993). Ascorbic acid is also a natural antioxidant used in foodstuff formulations in order to prevent browning, discolouring and also to enhance shelf-life. It is known to be thermolabile and its degradation mechanism is specific of a particular system, as it depends on several factors (Tannenbaum, 1976) following either aerobic or anaerobic pathways. The aerobic degradation pathway is related to the presence of oxygen (either in the headspace or dissolved) (TetraPak, 1998). The anaerobic 
Table 1

Kinetic parameters of thermal degradation of ascorbic acid in several fruits

\begin{tabular}{|c|c|c|c|c|c|c|c|c|}
\hline Product & $\begin{array}{l}\text { Temperature } \\
\text { range }\left({ }^{\circ} \mathrm{C}\right)\end{array}$ & $\mathrm{PH}$ & ${ }^{\circ}$ Brix & $\begin{array}{l}E a \\
\left(\mathrm{KJ} \mathrm{mol}^{-1}\right)\end{array}$ & $K_{O}\left(\mathrm{~s}^{-1}\right)$ & $\begin{array}{l}Z \\
\left({ }^{\circ} \mathrm{C}\right)\end{array}$ & $\begin{array}{l}D_{75^{\circ} \mathrm{C}} \\
(\min )\end{array}$ & Ref. \\
\hline $\begin{array}{l}\text { Grapefruit } \\
\text { juice }\end{array}$ & $61.0-96.0$ & 3.05 & 11.2 & 21.0 & $3.90 \times 10^{-2}$ & 49.3 & 1354 & Saguy et al., 1978 \\
\hline $\begin{array}{l}\text { Grapefruit } \\
\text { juice }\end{array}$ & $60.0-91.0$ & 3.05 & 31.2 & 22.0 & $6.10 \times 10^{-2}$ & 45.0 & 1228 & Saguy et al., 1978 \\
\hline Lime & $20.0-92.0$ & 5.92 & 6.3 & 58.1 & $1.55 \times 10^{4}$ & 35.8 & 1186 & Alvarado and Viteri, 1989 \\
\hline Lemon & $20.0-92.0$ & 2.94 & 6.0 & 46.5 & $3.59 \times 10^{2}$ & 44.6 & 949 & Alvarado and Viteri, 1989 \\
\hline Tangerine & $20.0-92.0$ & 4.10 & 13.4 & 44.6 & $2.25 \times 10^{2}$ & 46.5 & 771 & Alvarado and Viteri, 1989 \\
\hline Grapefruit & $20.0-92.0$ & 3.54 & 11.2 & 56.9 & $9.29 \times 10^{3}$ & 36.5 & 1276 & Alvarado and Viteri, 1989 \\
\hline $\begin{array}{l}\text { Orange } \\
\text { Juice }\end{array}$ & $70.3-97.6$ & 3.60 & 12.5 & 128.3 & $3.23 \times 10^{13}$ & 19.0 & 24110 & Johnson et al., 1995 \\
\hline $\begin{array}{l}\text { Orange } \\
\text { Juice }\end{array}$ & $70.3-97.6$ & 3.60 & 36.7 & 97.4 & $1.62 \times 10^{9}$ & 24.9 & 10447 & Johnson et al., 1995 \\
\hline $\begin{array}{l}\text { Orange } \\
\text { Juice }\end{array}$ & $\begin{array}{l}65-90 \\
\text { (conventional heating) }\end{array}$ & $\begin{array}{l}\text { Not } \\
\text { reported }\end{array}$ & $\begin{array}{l}\text { Not } \\
\text { reported }\end{array}$ & 12.6 & $3.30 \times 10^{4}$ & $\begin{array}{l}\text { Not } \\
\text { reported }\end{array}$ & $\begin{array}{l}\text { Not } \\
\text { reported }\end{array}$ & Lima, 1996 \\
\hline $\begin{array}{l}\text { Orange } \\
\text { Juice }\end{array}$ & $\begin{array}{l}65-90 \\
\text { (ohmic heating) }\end{array}$ & $\begin{array}{l}\text { Not } \\
\text { reported }\end{array}$ & $\begin{array}{l}\text { Not } \\
\text { reported }\end{array}$ & 12.5 & $3.26 \times 10^{4}$ & $\begin{array}{l}\text { Not } \\
\text { reported }\end{array}$ & $\begin{array}{l}\text { Not } \\
\text { reported }\end{array}$ & Lima, 1996 \\
\hline
\end{tabular}

pathway is independent of oxygen and is mainly driven by the storage temperature, lower temperature storage being the only way to minimise degradation rate (Trammell, Dalsis \& Malone, 1986). When oxygen is present the contribution of anaerobic degradation to the total vitamin $\mathrm{C}$ loss is small compared to aerobic degradation (Villota \& Hawkes, 1992). Several studies were made to determine the kinetic parameters of thermal degradation of ascorbic acid in food systems under conventional heating conditions (Table 1).

Strawberry fruit jams are extremely important for the Portuguese fruit jams industry because they account for most of the sales (approx. 90\%). The search for alternative processing technologies leading to higher quality products is, therefore, one of the main goals and the economic viability of this technology depends on the possibility of applying it to most of the products processed by this industry. One of the possible indicators for the effectiveness of the process is ascorbic acid degradation, leading to the need of establishing its degradation kinetics when subjected to ohmic heating.

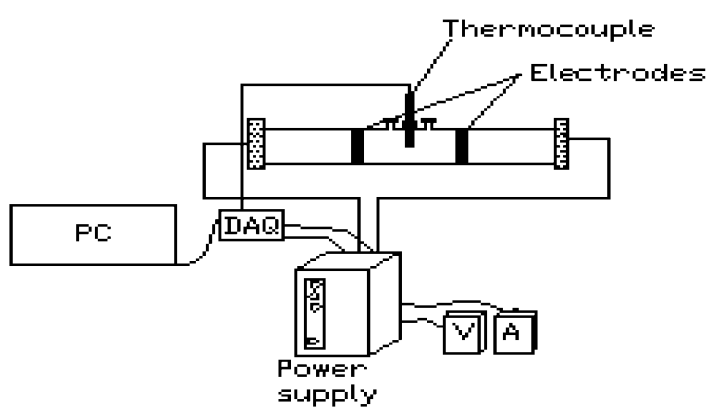

Fig. 1. Ohmic heater and data acquisition system.
The objectives of this work were then:

To determine the effects of different electrical field strengths on electrical conductivity values of several commercial strawberry-based products.

To evaluate the effects of multiple thermal treatments on electrical conductivity of two industrial strawberry pulps.

To study the effect of the electric field on the degradation rate of ascorbic acid, in strawberry industrial pulp.

To determine the kinetic parameters of ascorbic acid degradation under conventional and ohmic heating conditions.

\section{Materials and methods}

\subsection{System description}

The heater and data acquisition system used are represented in Fig. 1 and consisted of a cylindrical glass tube of $30 \mathrm{~cm}$ total length and $2.3 \mathrm{~cm}$ inside diameter. Three thermocouple openings were provided; two at an equal distance of the centre of the tube and one at the centre, where the thermocouple was placed. Two Titanium electrodes with Teflon pressure caps were placed at each end of the tube.

Samples were heated using an alternating current source, of $50 \mathrm{~Hz}$, with different field strengths. Temperatures were monitored using type- $K$ thermocouples, placed at the geometrical centre of the chamber.

A data-logger was employed to record continuously and simultaneously, current intensity, voltage and temperature. In order to measure voltage across and current through the samples voltage and current transducers 
were used. Electrical conductivity was determined by the following equation.

$\sigma=\frac{L}{A R}$

A, Inner cross sectional area of ohmic heater $\left(\mathrm{m}^{2}\right)$;

$L$, Interval between electrodes $(\mathrm{m})$;

$R$, Resistance $(\Omega)$;

$\sigma$, Electrical conductivity $\left(\mathrm{Sm}^{-1}\right)$.

Three replicates were made for each of the experiments described below.

\subsection{Strawberry products}

Frulact S.A., a Portuguese company producing fruit jams, provided strawberry pulps and the other strawberry-based products (strawberry topping, strawberry filling and strawberry-apple sauce).

Pulps were collected immediately before industrial pasteurisation and were transported under refrigerated conditions to the University of Minho. Experiments were conducted promptly in order to avoid microbiological deterioration, which might affect the results mainly due to the generation of carbon dioxide originating from the product's fermentation.

The pulp P1 used had an initial $\mathrm{pH}$ value of 4.0 , a Brix value of $14.5^{\circ}$ and $2.5 \%(\mathrm{w} / \mathrm{w})$ of starch content while pulp P2 had an initial $\mathrm{pH}$ value of 4.0 , a Brix value of $26.5^{\circ}$ and no starch. The other strawberry-based products were used as commercialized.

\subsection{Field strength experiments}

A set of experiments was conducted to determine the effect of field strength on the electrical conductivity changes during ohmic heating. The strawberry pulp samples were heated up to $100{ }^{\circ} \mathrm{C}$ using eight different field strengths (from 25 to $100 \mathrm{Vcm}^{-1}$ ) with a $2 \mathrm{~cm}$ gap between electrodes.

Strawberry based products were tested with four different field strengths (from 32 to $80 \mathrm{Vcm}^{-1}$ ) and a $2 \mathrm{~cm}$ gap between electrodes.

In all cases, the variation coefficient obtained between the three replicates made for each experiment was below $5 \%$.

\subsection{Multiple thermal treatments}

Changes in electrical conductivity of strawberry pulps P1 and P2 during multiple (2) thermal treatments were investigated. The pre-treatment by conventional heating was performed in the factory by pasteurization in a scrapped-surface heat exchanger and samples were collected for subsequent ohmic heating $(\mathrm{CH}+\mathrm{OH})$, during which the electrical conductivity was measured. For ohmic heating pre-treatment, raw samples of approximately $20 \mathrm{ml}$ were placed into the static ohmic heater and heated up to $100{ }^{\circ} \mathrm{C}$ once and were then collected for subsequent ohmic heating $(\mathrm{OH}+\mathrm{OH})$, for electrical conductivity determination. The same procedure was applied for the single ohmic heating treatment $(\mathrm{OH})$, were the samples were heated only once and electrical conductivity was measured.

In all cases, the variation coefficient obtained between the three replicates made for each experiment was below $5 \%$.

\subsection{Ascorbic acid degradation}

In order to compare the thermal degradation kinetics of the ascorbic acid in industrial strawberry pulps, ascorbic acid (Merck, 1.00127.0250) was added to the pulp P1 to obtain an initial concentration of approximately $0.5 \mathrm{~g} / 1$. Care was taken during the homogenization process to avoid air incorporation into the samples which might accelerate ascorbic acid degradation (Villota \& Hawkes, 1992).

For the constant temperature experiments, the temperature range used was between 60 and $97{ }^{\circ} \mathrm{C}$ for both heating processes (conventional and ohmic) using procedures detailed below. The kinetic parameters were calculated $\left(D, Z, E_{a}\right.$ and $\left.K\right)$. All the calculated kinetic parameters have associated a variation coefficient lower than $10 \%$.

$\frac{\log C_{A}-\log C_{A o}}{t}=\frac{1}{D}$

$\frac{\log D_{2}-\log D_{1}}{T_{2}-T_{1}}=\frac{1}{Z}$

$k(t)=k_{0} \exp \left(-\frac{E_{\mathrm{a}}}{R T}\right)$

$D$, Decimal reduction time (min);

$Z$, Temperature sensitivity indicator $\left({ }^{\circ} \mathrm{C}\right)$;

$E_{\mathrm{a}}$, Activation energy $\left(\mathrm{kJ} \cdot \mathrm{mol}^{-1}\right)$;

$K$, Frequency constant $\left(\mathrm{s}^{-1}\right)$;

$K_{0}$, Pre-exponential factor $\left(\mathrm{s}^{-1}\right)$.

\subsubsection{Ascorbic acid quantification}

For the quantification of ascorbic acid strawberry pulp was centrifuged (5 min, $10000 \mathrm{rpm}$ ) and the supernatant was used, to avoid interferences with the detection method. A commercial enzymatic kit was used to determine ascorbic acid concentration (kit Boehringer $\mathrm{N}^{\circ}$ 409677), obtained from Boehringer, Manhein, Germany (Castro, Gonçalves, Teixeira \& Vicente, 2002). Although not specifically required by the method's 


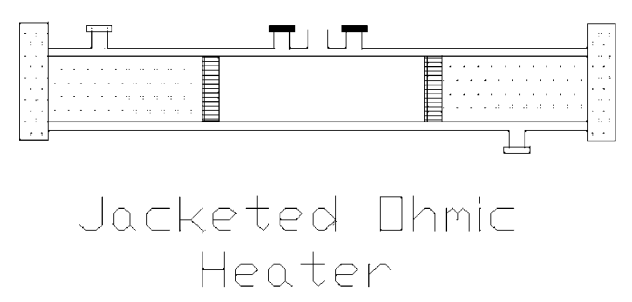

Fig. 2. Jackted ohmic heater.

instructions, a calibration curve was made in order to minimize the error associated with the samples measurement. The presented results are the averaged values of three assays. This analytical method measures only ascorbic acid so the other active compounds of vitamin $\mathrm{C}$ (such as dehydroascorbic acid) are not considered in this study.

\subsubsection{Conventional thermal degradation}

Samples of $1.75 \mathrm{ml}$ of strawberry pulp were placed in 2-ml Eppendorf tubes $(9 \mathrm{~mm}$ of internal diameter and $40 \mathrm{~mm}$ of height), in a thermostated water bath of the desired temperature, depending on the temperature assay. Samples were taken and placed immediately into ice to stop the thermal degradation effect. The dimensions of the Eppendorf tubes allowed to minimize temperature gradients due to heat transfer resistance.

The thermal history of the samples, until temperature stabilization, was monitored by the introduction of a thermocouple connected to the data acquisition system previously described. This procedure was made for each temperature with only one of the samples, which was not used to measure ascorbic acid because the introduction of air could cause ascorbic acid oxidation.

\subsubsection{Ohmic thermal degradation}

These sets of assays were made in an ohmic heater and data acquisition system similar to the one previously described except for the presence of a jacket in the ohmic heater to allow temperature control (Fig. 2). Samples of approximately $30 \mathrm{ml}$ of strawberry pulp were introduced into the heater and a type $\mathrm{K}$ thermocouple was placed into the geometric center of the heater to continuously monitor system temperature. Power source was turned on and electric field was varied in order to simulate the conventional thermal history of the samples. Comparison of the thermal history of the samples is presented in Fig. 3. It is very important to have coincidence in the heating phase of both processes because the objective is to compare the thermal effects of each treatment only.

The temperature holding phase was assured by making adjustments of the electric field intensity or the cold water flow rate. It should be stressed that the electric field strength used during the holding phase of the experiments is very low (in every case lower than 20
$\mathrm{V} \cdot \mathrm{cm}^{-1}$ ) when compared to the ones used in the heating phase of the samples.

For each sample, portions of $1.75 \mathrm{ml}$ were taken and placed immediately into ice to stop the thermal degradation effect. Samples volume was small to minimize temperature gradients due to heat transfer resistance.

\section{Results and discussion}

\subsection{Field strength experiments}

Figs. 4-8 show the electrical conductivity changes with field strength obtained for the different products tested. For all cases electrical conductivity increases with temperature although it may not be a linear relation. A linear relation between electrical conductivity and temperature is evident for the strawberry pulp P1, strawberry filling and strawberry-apple sauce (Figs. 4, 7 and 8) but this aspect changes for the strawberry pulp P2 and topping (Figs. 5 and 6) where a second order polynomial relation has been obtained. This second order polynomial relation may be due to the presence of air in the products. In an unpressurized heater, if air is occluded in the sample, the air bubbles will expand with temperature, with the pressure remaining constant. If ideal gas behaviour is assumed, then, the expansion will be linear in temperature. This would mean that bubble volume would increase linearly with temperature. However, the important parameter for electrical conductivity is the cross-sectional area of the bubbles in a plane perpendicular to the electric field. This will increase roughly as a two-thirds power of the volume. Thus air (which can be roughly considered to be of zero electrical conductivity) will increase in area, tending to reduce the electrical conductivity of the mixture. However, the continuous phase in itself will increase in electrical conductivity with the temperature, so the net effect will depend on the relative contribution of the components. Thus, as temperature increases, the in electrical conductivity of air may not be linear with temperature, so a non-linear model may well be justified.

The increase of electrical conductivity with field strength is clear for both strawberry pulps (P1 and P2) and strawberry filling. The heating process causes membrane destruction and consequently the free water content increases (Bean, Rasor \& Porter, 1960; Halden, De Alwis \& Fryer, 1990; Sasson \& Monselise, 1977). The field strength application results in increasing fluid motion through the capillaries, which is directly proportional to electrical conductivity (Halden et al., 1990). On the other hand, the effect of field strength is not as evident for the strawberry topping or strawberry-apple sauce and this behaviour may be either due to the small quantity of strawberry in products' formulation or to the fact that their previous processing already lead to membrane destruction so the increase of temperature 
$60^{\circ} \mathrm{C}$

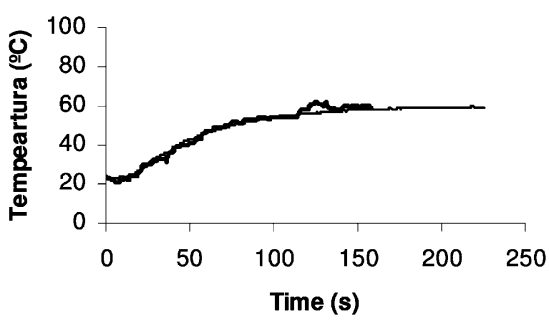

$75^{\circ} \mathrm{C}$

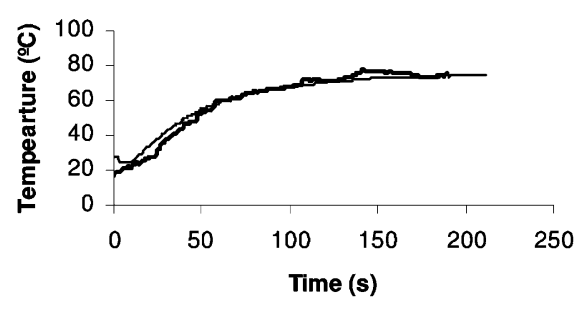

$90 \stackrel{\circ}{ } \div$

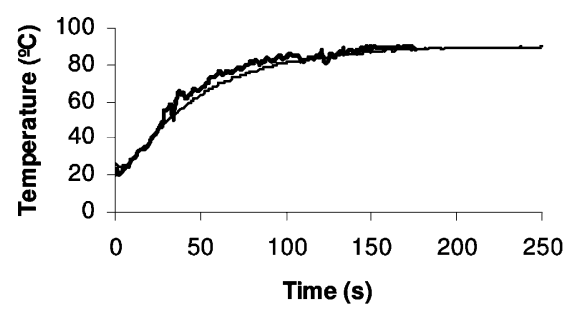

$70 \stackrel{\circ}{ } \mathrm{C}$

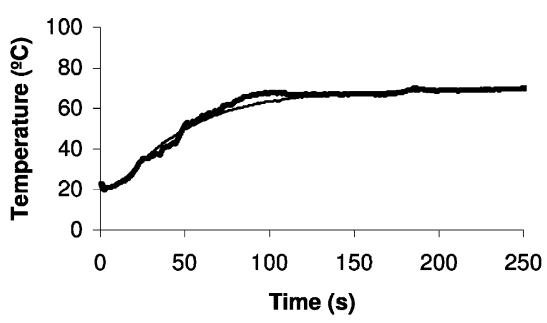

$80 \stackrel{\circ}{\circ}$

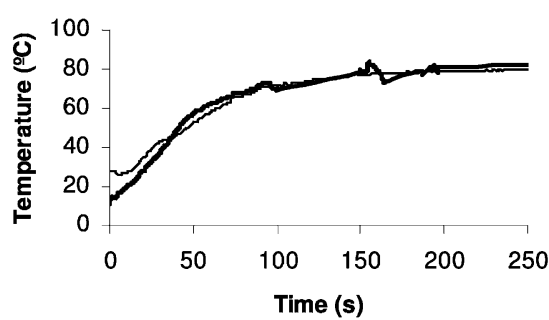

$97^{\circ} \mathrm{C}$

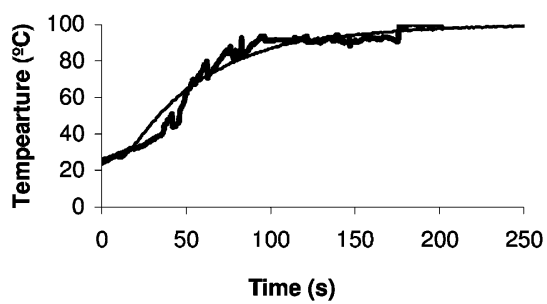

Fig. 3. Thermal history of the samples processed by conventional (-) and ohmic (-) heating.

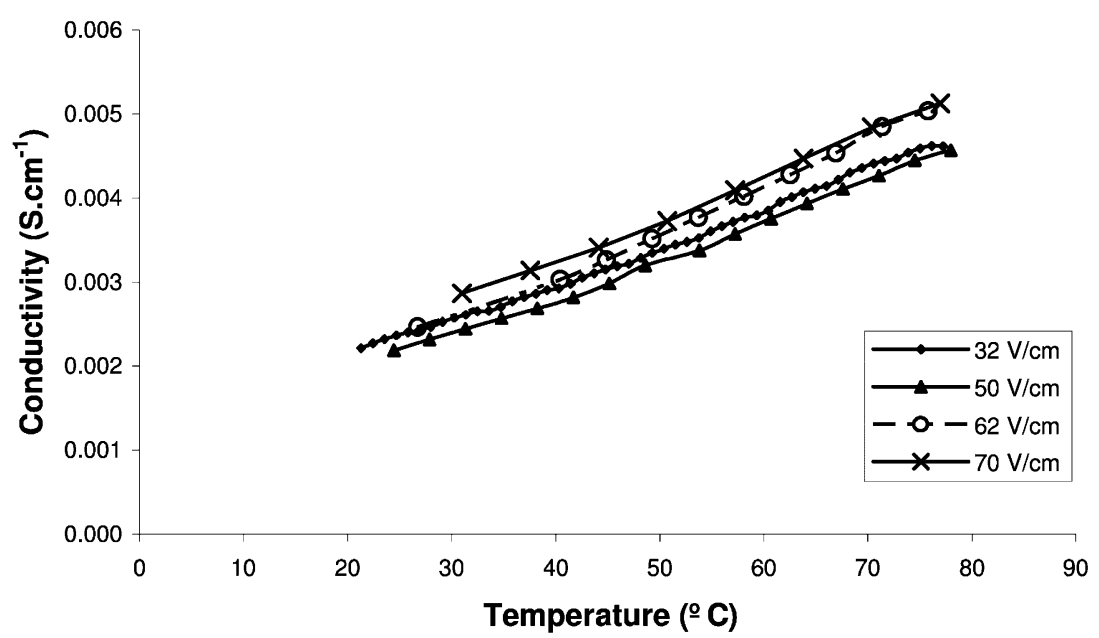

Fig. 4. Electrical conductivity of strawberry pulp P1, for different field strengths. 


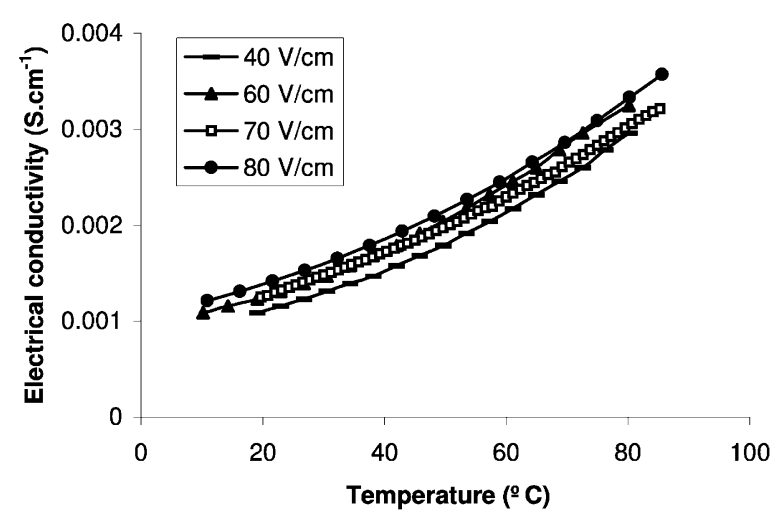

Fig. 5. Electrical conductivity of strawberry pulp P2, for different field strengths.

does not cause more structural changes and the mobility of the fluid and of the ionic components present is not further affected.

The differences in electrical conductivity values are reflected in the heating curves presented in Fig. 9. Strawberry topping has considerably lower electrical conductivity (5\% of the electrical conductivity of P1 and $19 \%$ of the electrical conductivity of P2) and a consequently lower heating rate $\left(0.3{ }^{\circ} \mathrm{Cs}^{-1}\right.$ comparing to $1.60{ }^{\circ} \mathrm{Cs}^{-1}$ for $\mathrm{P} 2$ and $6.22{ }^{\circ} \mathrm{Cs}^{-1}$ for the pulp P1) that would indicate the use of a different ohmic heater design for this product. This shows the importance of evaluating the electrical properties of a food intended to be processed by ohmic heating by clearly demonstrating the significant differences of electrical conductivity between the several products tested.

\subsection{Multiple thermal treatments}

Analysing Figs. 10 and 11 it is evident that the absolute values of conductivity are much different between pulps $\mathrm{P} 1$ and $\mathrm{P} 2$, leading to average heating rates of 6.22 and $1.60{ }^{\circ} \mathrm{Cs}^{-1}$, respectively. This difference is due to the higher content of ionic constituents (citric acid and sodium citrate) of P1 as compared to $\mathrm{P} 2$. In fact, the higher the concentration of ionic constituents, the higher the conductivity of the product (Halden et al., 1990).

When comparing samples treated with ohmic heating alone $(\mathrm{OH})$ and with a combination of conventional heating and ohmic heating $(\mathrm{CH}+\mathrm{OH})$ or ohmic heating plus ohmic heating $(\mathrm{OH}+\mathrm{OH})$ it is evident that the

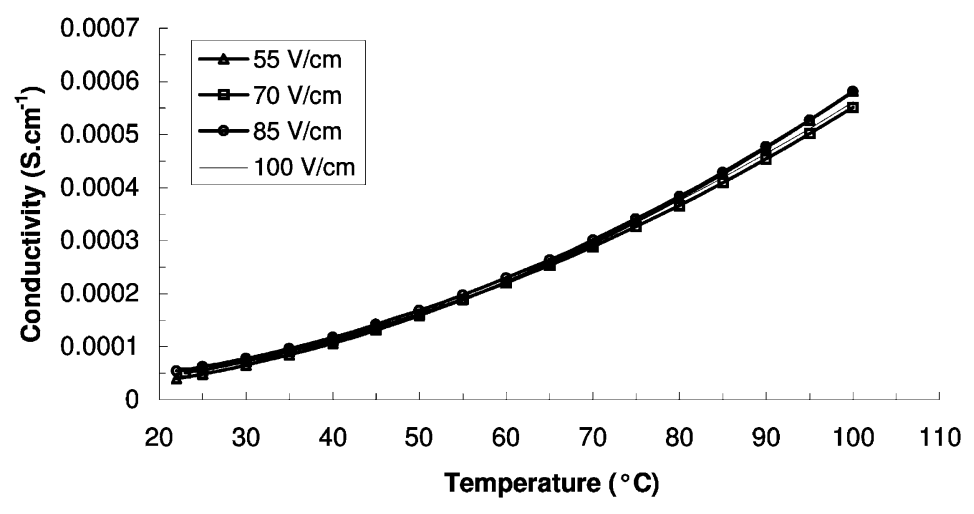

Fig. 6. Electrical conductivity of strawberry topping, for different field strengths.

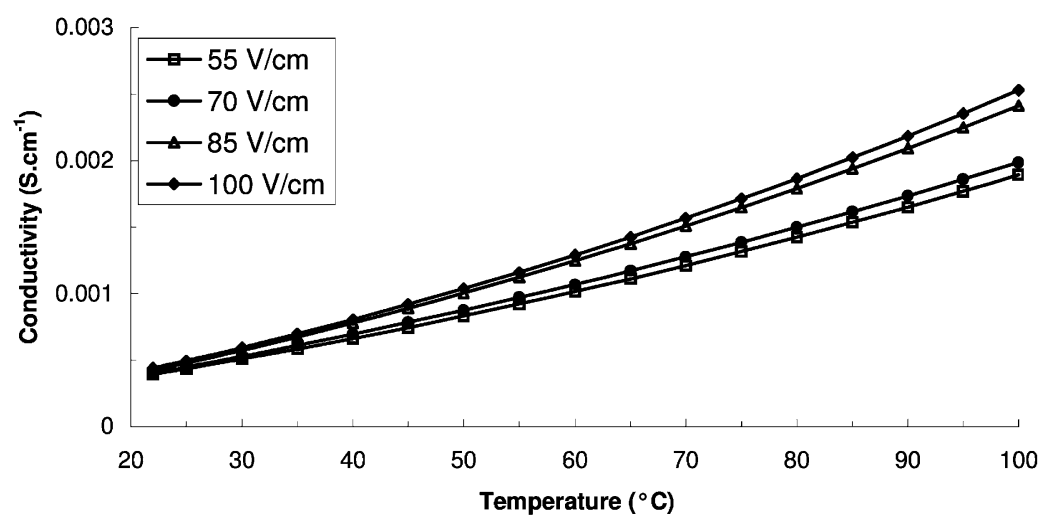

Fig. 7. Electrical conductivity of strawberry filling, for different field strengths. 


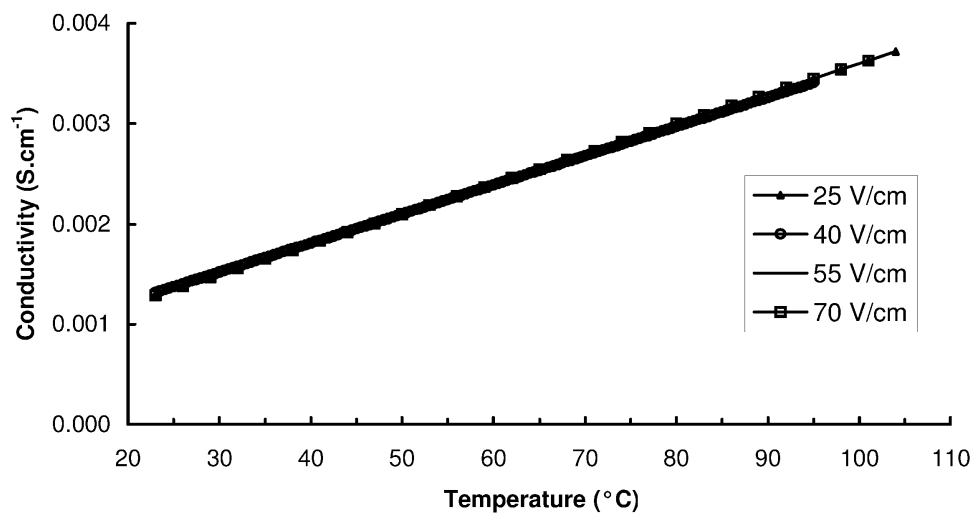

Fig. 8. Electrical conductivity of strawberry-apple sauce, for different field strengths.

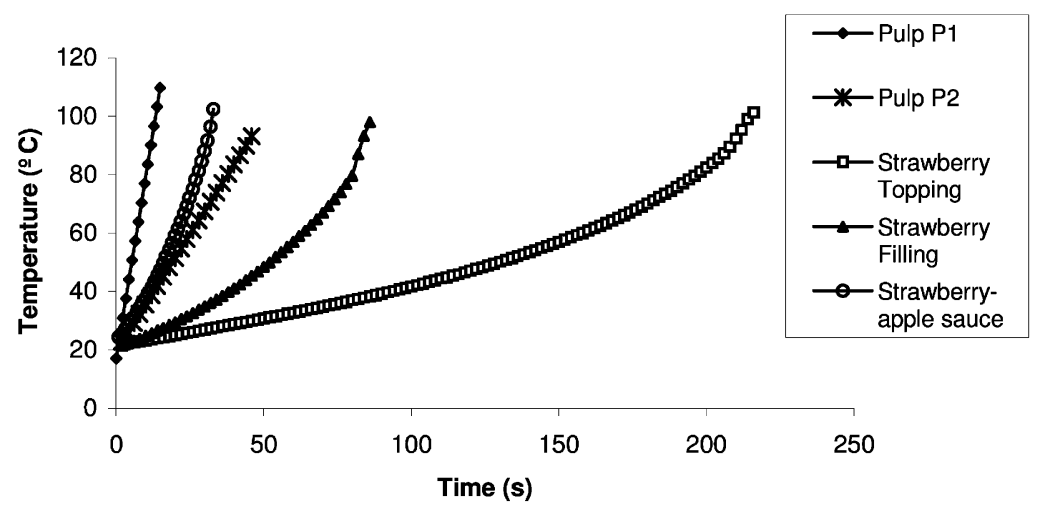

Fig. 9. Heating curves of strawberry and strawberry products, during ohmic heating, with field strength of $70 \mathrm{Vcm}$.

electrical conductivity decreases after the first thermal treatment for both cases (Figs. 10 and 11). The raw samples $(\mathrm{OH})$ present the highest electrical conductivity value while the lowest value is found after two ohmic cycles. These results are opposite from the ones reported by Wang and Sastry (1997) in vegetable samples. The structural changes caused by heating that should lead to

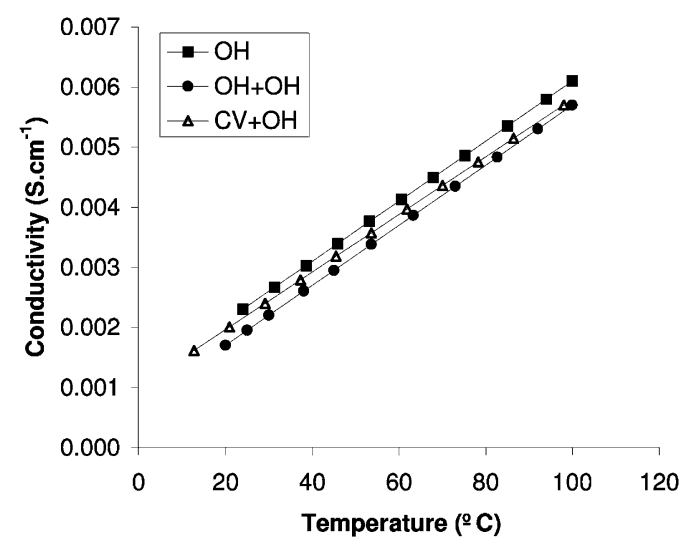

Fig. 10. Electrical conductivity changes of strawberry pulp P1 during multiple thermal treatments. an increase of electrical conductivity are probably counterbalanced by water evaporation during the heating process, reducing the fluid motion and the electrical conductivity values. This has been confirmed by the measurement of the Brix values before and after the treatment (Brix increased from 14.5 to 16.0 for pulp P1 and from 26.5 to 28.5 for pulp P2). The decrease in electrical conductivity with thermal treatments is less evident for P1 probably because starch gelatinization

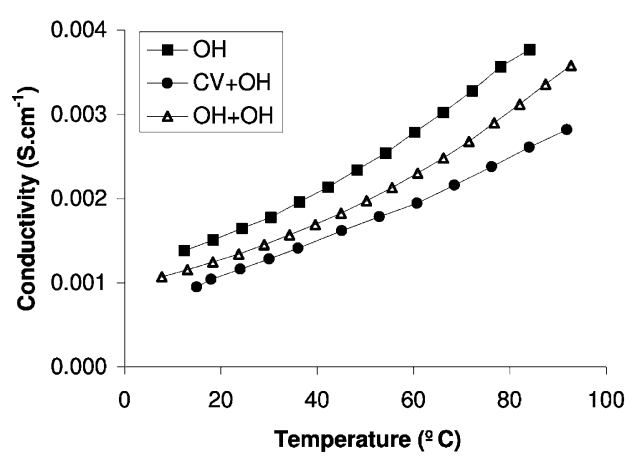

Fig. 11. Electrical conductivity changes of strawberry pulp P2 during multiple thermal treatments. 

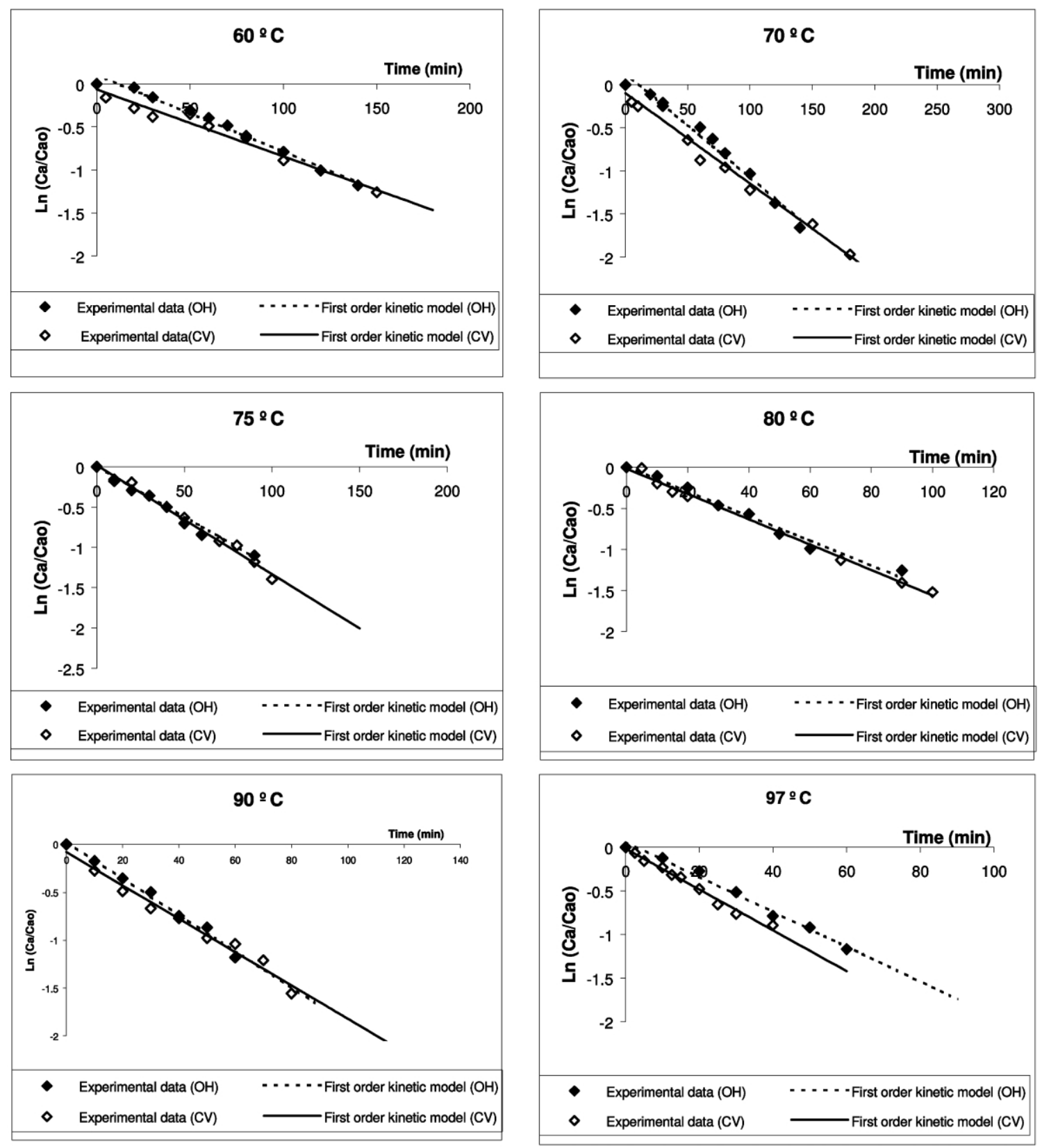

Fig. 12. Ascorbic acid degradation when processed by conventional and ohmic heating: experimental data and first order degradation kinetics fitting.

$(2.5 \% \mathrm{w} / \mathrm{w})$ and the resulting change in water binding capacity, thus preventing its loss to the atmosphere; also, viscosity may increase, which may reduce electrical conductivity. In formulation P2 there are no hydrocolloids present and therefore dehydration is facilitated.

The sample P1 pre-treated by conventional heating showed higher values of electrical conductivity than when pre-treated by ohmic heating. This finding is consistent with work relating to starchy materials. Previous work with starchy materials (Wang \& Sastry, 1997) has shown that preheating by conventional methods may result in greater starch gelatinisation and a greater subsequent increase in electrical conductivity, than ohmically heated samples (where heating is very rapid and sufficient time may not be available for complete gelatinisation). On the other hand, P2 presented higher electrical conductivity when preheated by ohmic heating. This behaviour can be explained by different formulation and lower electrical conductivity values than $\mathrm{P} 1$ so the ohmic process might induce structural changes causing the obtained increase.

\subsection{Ascorbic acid degradation}

The effect of temperature and time on the degradation 
Table 2

Kinetic parameters of thermal degradation of ascorbic acid in strawberry pulp

\begin{tabular}{lllllll}
\hline Temperature $\left({ }^{\circ} \mathrm{C}\right)$ & 60 & 70 & 75 & 80 & 90 & 97 \\
\hline$D_{\text {conventional }}(\min )$ & 294 & 196 & 175 & 152 & 123 & 111 \\
$r^{2}$ & 0.999 & 0.981 & 0.986 & 0.998 & 0.993 & 0.991 \\
$D_{\text {ohmic }}(\mathrm{min})$ & 256 & 192 & 169 & 154 & 130 & 114 \\
$r^{2}$ & 0.987 & 0.980 & 0.985 & 0.981 & 0.995 & 0.988 \\
$Z_{\text {conventional }}\left({ }^{\circ} \mathrm{C}\right)$ & $\mathbf{4 6 . 7 3}\left(r^{2}=0.995\right)$ & & & \\
$Z_{\text {ohmic }}\left({ }^{\circ} \mathrm{C}\right)$ & $\mathbf{4 6 . 7 3}\left(r^{2}=0.999\right)$ & & & \\
$K_{\text {o conventional }}\left(\mathrm{s}^{-1}\right)$ & $\mathbf{0 . 1 5}\left(r^{2}=0.986\right)$ & & & \\
$K_{\mathrm{o} \text { ohmic }}\left(\mathrm{s}^{-1}\right)$ & $\mathbf{0 . 1 4}\left(r^{2}=0.991\right)$ & & & \\
$E_{\text {a conventional }}\left(\mathrm{kJ} \cdot \mathrm{mol}^{-1}\right)$ & 21.36 & & & & \\
$E_{\text {a ohmic }}\left(\mathrm{kJ} \cdot \mathrm{mol}^{-1}\right)$ & 21.05 & & & & \\
\hline
\end{tabular}

of ascorbic acid is presented in Fig. 12, for conventional and ohmic heating.

Thermal degradation of ascorbic acid follows first order degradation kinetics for both conventional and ohmic heating, in the studied temperature range (60 to $\left.97{ }^{\circ} \mathrm{C}\right)$.

Rate constants $(k)$ for both conventional and ohmic processes were plotted against the reciprocal of absolute temperature to determine frequency factor $\left(k_{0}\right)$ and activation energy $\left(E_{\mathrm{a}}\right)$. The kinetic parameters listed in Table 2 were obtained by fitting the data to the Arrhenius equation (Eq. (4)). The obtained kinetic parameters were identical for the two types of heating processes leading to the conclusion that the presence of an electric field does not affect the ascorbic acid degradation. Lima (1996) took similar conclusions for orange juice systems. The measured kinetic parameters are within the range of the values found in published literature for other food systems under conventional heating conditions (see Table 1). The only reference found where kinetic parameters under ohmic heating conditions were determined (in orange juice) (Lima, 1996) presented slightly higher values than the ones obtained in this work.

\section{Conclusions}

It is important to determine electrical conductivity in order to decide on the applicability of ohmic heating technology for specific products. In all cases considered, electrical conductivity increases with temperature, presenting linear or second order relations, depending on the product.

For some of the products tested the field strength does not affect electrical conductivity but for both strawberry pulps (P1 and P2) the differences are noticeable. In some cases (depending on the temperature), for a $40 \%$ increase in the field strength, the electrical conductivity increases $30 \%$.

Thermal treatments affect significantly electrical con- ductivity values (decreasing with thermal treatments) for both strawberry pulps (P1 and P2). The effect of a conventional or ohmic pre-treatment is different for the two samples. In strawberry pulp P1 a conventional preheating process leads to higher electrical conductivity values then an ohmic process, probably due to its starchy composition. Sample P2 (without texturizing agents) shows a higher electrical conductivity when an ohmic pre-treatment process is applied, as compared to the conventional pre-treatment.

The ascorbic acid degradation kinetics in strawberry industrial pulps for the temperature range of 60 to 97 ${ }^{\circ} \mathrm{C}$ were unaffected by lower values of the electric field strength $\left(<20 \mathrm{~V} \cdot \mathrm{cm}^{-1}\right)$. Ascorbic acid degradation followed first order kinetics for both conventional and ohmic heating treatments and the kinetic constants were in the range of the values reported in the literature for other food systems.

\section{References}

Alvarado, J. D., \& Viteri, N. P. (1989). Efecto de la temperatura sobre la degradacion aerobica de vitamina $\mathrm{C}$ en jugos de frutas cítricas. Archivos latinoamericano de Nutricion, 39(4), 601.

Bean, E. C., Rasor, J. P., \& Porter, G. C. (1960). Changes in electrical conductivities of avocados during ripening. Year Book of Californian Avocado Society, 44, 75-78.

Castro, I., Gonçalves, O. Teixeira, J. A., Vicente, A. A. (2002). Comparative study between Selva strawberries and other varieties for industrialization. Journal of Food Science (forthcoming).

Gregory, J. F. (1993). Ascorbic acid bioavailability in foods and supplements. Nutrition Reviews, 51(10), 301-313.

Halden, K., De Alwis, A. A., \& Fryer, P. J. (1990). Changes in the electrical conductivity of foods during ohmic heating. International Journal of Food Science Technology, 25, 9-35.

Lima, M. (1996). Ascorbic acid degradation kinetics and mass transfer effects in biological tissue during ohmic heating. PHD dissertation, Ohio State University.

Johnson, J. R., Braddock, R.J, \& Chen, C. S. (1995). Kinetics of ascorbic acid loss and nonenzymatic browning in orange juice serum: experimental rate constants. Journal of Food Science, 60(3), 502 .

Mizrahi, S., Kopelman, I., \& Perlaman, J. (1975). Blanching by electroconductive heating. Journal of Food Technology, 10, $281-$ 288.

Saguy, I., Kopelmaan, I. J., \& Mizrah, S. (1978). Simulation of ascorbic acid stability during heat processing and concentration of grapefruit juice. Journal of Food Process Engineering, 2, 213.

Sasson, A., \& Monselise, S. P. (1977). Electrical conductivity of Shamouti orange peel during fruit growth and postharvest senescence. Journal of American Society of Horticultural Science, 102, $142-144$.

Sastry, S. K., Yousef, A., Cho, H Y., Unal, R., Salengke, S., Wang, W. C., Lima, M., Kulshrestha, S., Wongsa-Ngasri, P., Sensoy, I. 2001. Ohmic Heating and Moderate Electric Field (MEF) Processing. In: Engineering and Food for the 21st Century. Technomic Publishers (in press).

Tannenbaum, S. (1976). Ascorbic acid. In O. Fennema, Principles of food science. part I. Food chemistry, 2nd ed. (Chapter 7) . New York: Marcel Dekker. 
Tetra Pak. (1998). The Orange Book. Tetra Pak Processing systems $\mathrm{AB}$, Lund, Sweden.

Trammell, D. J., Dalsis, D. E., \& Malone, R. T. (1986). Effect of oxygen on taste, ascorbic acid loss and browning for HTSTpasteurize, single strength orange juice. Journal of Food Science, 61(3), 477-489.
Villota, R., \& Hawkes, J. G. (1992). Reaction kinetics in food systems. In D. Heldman, D. Lund, Handbook of engineering. (Chapter 2) . New York: Marcel Dekker Inc.

Wang, W., \& Sastry, S. K. (1997). Changes in electrical conductivity of selected vegetables during multiple thermal treatments. Journal of Food Proceedings Enger, 20, 499-516. 